\title{
Employee Perceptions of Well-Being Programs
}

\author{
Alice V. Edwards \\ Walden University \\ Susan Marcus \\ Walden University
}

\begin{abstract}
Measuring the effectiveness of well-being programs in the workplace is important for optimizing the return on investment and selection of programs that meet organizational objectives. A pilot study was performed to assess employee well-being using the Happiness Mini-Survey and a one-sample pre-post study design intended to quickly allow employees to subjectively rate their well-being before and after participating in various classes as part of a well-being program. The findings demonstrated statistical significance in employee subjective ratings; they reported feeling better emotionally, physically, and mentally after participating in the classes. The employees' self-rating for stress level also had statistically significant improvement after class participation. These findings are relevant for organizations that intend to offer and evaluate classes with an objective of increasing employee well-being. Recommendations for future studies include the use of more controlled conditions, and a control or comparison group to more robustly test for improvement over time, and the use of qualitative interviews to discover employees' narratives of how workplace well-being programs can improve work productivity and quality of life.
\end{abstract}

Keywords: well-being, workplace, happiness survey, stress management, work-life balance, psychological safety, perceived organizational support, work-related stress, emotional labor, technology

\section{Introduction}

Despite the progress of medicine in the United States, the economic and human-resource costs of employee illness continue to influence how employers manage productivity and growth. Asay, Roy, Lang, Payne, and Howard (2016) determined that absenteeism due to smoking, physical inactivity, obesity, hypertension, and diabetes cost American employers an estimated $\$ 36.4$ billion dollars. The National Alliance on Mental Illness (n.d.) reported that one in every five adults experiences a mental health condition each year, which can be brought on by a number of factors, including job stress. Insel (2008) estimated that serious mental illness costs American workers over $\$ 193$ billion annually and that the total economic impact of mental illness was over $\$ 317$ billion. Missing from this figure are costs related to lesser degrees of illness that reduce productivity such as presenteeism (going to work while ill, e.g., Miraglia \& Johns, 2016), which occupational health psychologists have linked to both mental and physical health (Pohling, Buruck, Jungbauer, \& Leiter, 2016).

Hart and Cooper (2014), developers of the organizational health framework, considered employee well-being a critical function in achieving greater organizational performance. In the past, organizations looked to health insurance and employee assistance programs to help alleviate these problems. Increasingly, organizations are seeing the value in implementing structured well-being programs to prevent illness and improve employee well-being (Spence, 2015). This growing number

Please address queries to: Alice V. Edwards, School of Psychology, Walden University, 100 South Washington 
of workplaces that see the economic and social value of workplace wellness marks a significant milestone in the evolution of the worksite health model.

Worksite well-being has been growing in popularity since the 1970s (Conrad, 1988). Initial evidence for worksite well-being having benefits to organizations was presented by Eisenberger, Huntington, and Hutchinson (1986), who found that perceived organizational support was a predictor of lower absenteeism and employee effectiveness. The advancement of technology and global marketplace has created a highly competitive marketplace for highly skilled workers. This has contributed to the momentum of the workplace well-being movement as some organizations have begun utilizing wellbeing programs as part of corporate social responsibility initiatives (Krainz, 2015). As the interest and research in this arena has continued, findings have demonstrated the social influence implementing well-being programs has on overall employee well-being because health benefits do not stop when an employee leaves the office premises. For example, researchers reported that employees reported eating more fruit and vegetables after seeing other coworkers eating fruits and vegetables (Tabak, Hipp, Marx \& Brownson, 2015); these changes in healthy eating habits are a positive lifestyle change. Similarly, when health initiatives were implemented at the National Health Service for their employees including providing access to alternative medicines and treatments including massage, employees reported benefits including increased self-awareness, relaxation, better coping, self-esteem, and happiness (Meade, MacLennan, Blake, \& Coulson, 2009). Even more promising, the body of research demonstrating return on investment for increasing organizational supports including wellness initiatives is increasing (Berry, Mirabito \& Baun, 2010; Eisenberger et al., 1986; Mukhopadhyay \& Wendel, 2013; Parks \& Steelman, 2008). Johnson and Johnson (as cited in Berry et al., 2010), reported that their wellness initiatives have not only cut the number of employees who smoke by more than two-thirds and significantly decreased the number of employees who have high blood pressure or are physically inactive, but they have also saved the company an estimated $\$ 250$ million in healthcare costs over a 10-year span.

Well-being programs, defined here as any program designed to teach employees ways in which they can increase their physical health or mental health, come in a variety of plans and delivery methods. While some organizations provide sporadic well-being initiatives, Spence (2015) defined a more cohesive workplace well-being program as one where those programs included health and illness prevention and structured programs that sought to incorporate wellness and included an assessment component.

Parks and Steelman's (2008) meta-analysis identified that participation in wellness programs contributed to lower absenteeism and higher job satisfaction. Baicker, Cutler, and Song's (2010) meta-analysis substantiated Parks and Steelman's (2008) work, and identified cost savings associated with well-being measures, finding that for every dollar spent on wellness programs, medical costs decrease by $\$ 3.27$ and absenteeism costs fall by about $\$ 2.73$, for a total cost savings of $\$ 6.00$ per dollar spent on wellness programs. This phenomenon is not limited to the United States; countries outside the United States are investing in well-being programs as well. Recently, Australia's National Mental Health Commission published a report (PricewaterhouseCoopers, 2017) demonstrating an average return on investment for Australian organizations of $\$ 2.30$ per dollar spent on well-being with savings in areas including presenteeism, absenteeism, and workers' compensation claims.

Much research has been completed to document whether well-being programs are valuable to the workplace and how they support organizational growth through either increased productivity or reduced costs. Researchers have demonstrated the negative effects of not addressing employee well- 
being. For example, in a systematic review of studies conducted on healthcare professionals, Hall, Johnson, Watt, Tsipa, and O'Connor (2016) identified a significant correlation between low wellbeing scores of the healthcare professionals and patient safety. Other researchers have demonstrated positive benefits to employers who address various aspects of employee well-being, for example, supportive leadership behavior reduces absenteeism, presenteeism, and the related costs for each (Schmid et al., 2017). Where wellness programs provided a good return on investment, common features included strong leadership support, worksite policies that supported healthy behaviors, incentives for employees to participate, and the incorporation of positive behavior-change programs (Archer, 2012). In cases where well-being programs were unsuccessful, a primary underlying factor has been the lack of overall positive culture or workplace environment to support well-being measures (Spence, 2015). A variety of programs have been tested for prevention or reduction of workplace illness with demonstrable efficacy including for depression (Tan et al., 2013).

Despite the promising results of these and many other reports, more work remains to be done in evaluation of well-being programs. As Zungu and Setswe (2007) noted in their review of well-being programs being performed across the globe, most well-being programs are being offered in large organizations in rich industrialized countries which already have the healthiest workers, from a global perspective of health. Considered from this vantage point, it is important to be able to show the benefit of well-being programs to employers of every size and budget, and to provide tools and ways to measure well-being that do not require large corporate budgets.

\section{How Well-Being Programs Are Evaluated}

Well-being programs are the subject of a growing number of research studies (Russell et al., 2016). With so many different well-being programs and program providers, there is need for programs to be able to demonstrate measurable benefits (Archer, 2012). Many models exist that evaluate employee well-being from different perspectives. The most common style is to use a Likert scale to examine a number of questions. Most use a quantitative, rather than a qualitative approach. Survey lengths for measuring employee well-being vary from some that have 40 (Shuck \& Reio, 2014) or 50 (Parker \& Hyett, 2011) or more questions for employees to answer, to some models with as few as three questions, including Iverson, Olekalns, and Erwin's (1998) three-item scales for emotional exhaustion, depersonalization, and personal accomplishment. Differing views exist on what should be measured including what areas to emphasize (e.g., psychological, physiological, or social aspects or short- or long-term states of well-being; Warr, 2014).

To support the increasing trend in well-being programs, a growing number of tools exists for organizations to measure well-being and performance, but there is no consensus regarding which measurement is the best (Kaare \& Otto, 2015; Kuykendall \& Tay, 2015; Mukhopadhyay \& Wendel, 2013; Slemp, Kern, \& Vella-Broderick, 2015; Spence, 2015). Additionally, the existing tools are designed for scientific rigor rather than practical daily use in the field. The current body of research and marketplace tools does not provide low-cost, simple-to-use mechanisms for program organizers and trainers to evaluate the benefit of the program to the participants and the organization. The current study evaluates the potential of a new short-form survey as a mechanism for program organizers or well-being program teachers to measure the change in well-being as a response to program participation as well as provide feedback to individual employees. 


\section{Conceptual Framework}

Mitchell and Daniels (2003) proposed that improvements in affect and mood, positive changes in beliefs and values, improved physical environment, rewards, positive organizational culture, and social norms that employees viewed as positive all contributed to improved motivational processes, improved use of skills and facilitated in optimal employee performance. Bakker (2015) built upon this idea in proposing a multilevel approach to understanding employee well-being, which he suggested is necessary for the complex interactions between employee's physiological and psychological dynamics to evaluate workplace well-being. Bakker's model demonstrates that job performance is affected by employee well-being, as well as by other factors including personality, and job demands in ways that produce either positive or negative effects. Bakker's (2015) model is supported by affective events theory (AET; Weiss \& Cropanzano, 1996) and broaden-and-build theory (Fredrickson, 2001). AET demonstrates how employee reactions to workplace events trigger emotional responses that affect employee behaviors, attitudes, and well-being (Ilies, Aw, \& Pluut 2015). Broaden-and-build theory supports the position that when employees experience more positive emotions they will be more productive (Shuck \& Reio, 2014). This is further supported by Kuykendall and Tay's (2015) research, which demonstrated how the employee's subjective well-being score was linked to workplace physiological functioning. Furthermore, research on self-efficacy has also demonstrated that when employees believe they have what they need to accomplish their tasks, it has positive effects on employee engagement and life satisfaction (Chanchal \& Divya, 2015). In summary, these theories and research demonstrate that employees' subjective perception of wellbeing may be related to health and productivity outcomes.

\section{Methodology}

The purposes of this pilot study were to (a) assess the utility of the Happiness Mini-Survey in efficiently measuring employee well-being and (b) examine the data collected at two points in time to assess differences in self-reported well-being after participating in well-being classes. In February 2017, the researchers worked with Wellshift, an organization providing well-being classes to corporate clients, and utilized (with their permission) a modified version of their self-report questionnaire to detect changes from pre- to postprogram participation. There was no control group, resulting in utilization of a simple single-factor design to answer the hypothesis of whether there was a measurable difference in pre- and posttest scores. Dependent-samples $t$ tests were used to assess change over time.

\section{Participants}

The study took place in a Fortune 500 technology company located in the Southwest in February 2017. Approximately 435 employees were invited to participate in a series of wellness classes designed to improve physical and mental health. Of those, 78 employees participated in the classes and completed pre- and postclass questionnaires (Edwards, 2017) at the start and end of the 1-hr class.

\section{The Program}

The Wellshift program provided classes on health and wellness to organizations since 2012 (Wellshift, 2017). The implementation of programs varies by organization. For the company in this study, Wellshift created an offering of five classes at three corporate campuses. Each class was offered at least twice. The topics of these classes covered stress management (Phillips, 2017), 
mediation (Jasso, 2017), personal finance (Bera, 2017), interpersonal relationships (Howard, 2017), and communication and presentation skills (Zamcheck, 2017).

\section{Instrumentation}

The Happiness Mini-Survey was created with the intention to provide the well-being class instructor a mechanism for (a) allowing students to cognitively process how they felt in the present moment both before and after a class, and (b) allow both the students and the class instructor to quickly be able to assign a numeric value to how participating in the class contributed to the students feeling of happiness and well-being.

In the Happiness Mini-Survey, four questions were asked using a 5-point Likert-type agreement scale where 5 was the positive anchor and 1 was the negative anchor. The four questions were chosen after a review of Kuykendall and Tay's (2015) research on the influence of subjective wellbeing on workplace functioning particularly how positive emotions, physical health, and stress impact employee functioning at work, utilizing the broaden-and-build theory for how positive emotion leads to different courses of actions then negative emotions. Lee, Joo, and Choi's (2013) research on perceived stress provided the justification for Item 4. Elo, Leppänen, and Jahkola (2003) validated the use of single-item measurement for stress and well-being in drawing reliable grouplevel conclusions; their work is supported by Dolbier, Webster, McCalister, Mallon, and Steinhardt's (2005) similar conclusions regarding the correlations found between a single-item measurement for job satisfaction and related scores on health measurements.

The questions have been used in prior research and are adapted from Eastman's (1996) concept of a worker well-being report card. The subjective real-time reporting method is used based on Kahneman and Krueger (2006) findings that when measuring subjective well-being quantitatively, individuals struggle with reliable retrospective measurements but can reliably measure in real-time. Respondents answered the following four questions.

- How do you feel mentally? This question is adapted from the work of Järvholm, Broberg, and Thurin-Kjellberg (2014) and Horneij, Holmström, Hemborg, Isberg, and Ekdahl (2002).

- How do you feel physically? This question is adapted from the work of Horneij et al. (2002); Fleming, Ruble, Flett, and Van Wagner (1990); Krystal (2005); and Wells (2006).

- How do you feel emotionally? This question is adapted from the work of Fleming et al. (1990), Krystal (2005), and Wells (2006).

- How's your stress level? This question is adapted from the work of Eastman (1996).

Reponses were on a scale from 5 (awesome), 4 (good), 3 (meh), 2 (been better), and 1 (rough). Meh is an interjection defined by Merriam-Webster (2018) as "used to express indifference or mild disappointment." It is interesting to note that Merriam-Webster dates the first-known use of meh back to 1992 .

In terms of content validity, Dolbier et al. (2005) and Scarpello and Campbell (1983) proposed and validated that one item is adequate for evaluating an overarching topic, such as job satisfaction, suggesting that more questions are valuable only when the researcher desires to delve into some of the underlying factors and supports within the larger topic. 
The researchers found that there were no misinterpretations of the items and 78 participants completed all questions at both pre- and posttest. Cronbach's alpha demonstrated acceptable internal consistency for the four pretest items $(\alpha=.74)$, and high internal consistency for the posttest $(\alpha=.82)$. Interitem reliability analysis identified that removal of any question would have resulted in a lower Cronbach's alpha score, with the exception of the question about physical health, on the posttest which would have shown a very small increase $(\alpha=.83)$.

\section{Procedures}

Wellshift used the survey over a 2-month period in early 2017, onsite at a Fortune 500 company (Weinberger, 2017) for 10 classes, two each of the five topics chosen by the organization. Participants were instructed to complete the side marked "pre" prior to the start of class, and then set it aside until the end of the class. When the class concluded, the staff member asked participants to turn it over and complete the "post" side of the survey, then leave the survey on their seats as they left the room. Wellshift staff then collected the surveys and provided the completed survey responses to the researchers.

\section{Results}

\section{Scoring}

The Happiness Mini-Survey results were scored by adding up the total numeric value of the four questions on the pretest, adding up the total numeric value of the four questions on the posttest, and subtracting the pretest value from the posttest value to arrive at an improvement variance as shown in mean variance on each question and total score in Table 3. A minimum total score of 4 is possible if an individual rated themselves as a 1 for each question, while the maximum score would be 20 .

\section{Descriptive Analyses}

Only two cases had one item missing, so the summary scores of the posttest contained 78 cases. These results show that from pre- to posttest, scores improved, with summary scores changing from 13.91 to 16.22 , with a net change of +2.31 improvement (see Table 1). Levene's test confirmed that the summary score distributions were sufficiently normal to meet repeated measures t-test requirements, $F(4,73)=1.81, p=.135$. 
Table 1. Descriptive Statistics of Well-Being Measures

\begin{tabular}{lccccc}
\hline $\begin{array}{l}\text { Well-Being } \\
\text { Aspects }\end{array}$ & $\boldsymbol{N}$ & Minimum & Maximum & $\boldsymbol{M}$ & $\boldsymbol{S} \boldsymbol{D}$ \\
\hline Pretest & & & & & \\
$\quad$ Mental & 80 & 1 & 5 & 3.68 & 0.74 \\
Physical & 80 & 1 & 5 & 3.59 & 0.82 \\
Emotional & 80 & 1 & 5 & 3.61 & 0.77 \\
Stress & 80 & 1 & 5 & 3.04 & 0.85 \\
$\quad$ Total & 80 & 7 & 19 & 13.91 & 2.39 \\
Posttest & & & & & \\
Mental & 79 & 2 & 5 & 4.30 & 0.59 \\
Physical & 79 & 2 & 5 & 3.94 & 0.67 \\
Emotional & 80 & 2 & 5 & 4.14 & 0.65 \\
Stress & 80 & 10 & 5 & 3.86 & 0.67 \\
$\quad$ Total & 78 & & 20 & 16.22 & 2.07 \\
Valid $N$ & 78 & & & & \\
\hline
\end{tabular}

Note. Minimum possible on the pretest and posttest Total was 4, maximum possible was 20.

\section{Hypothesis Testing}

To evaluate the statistical significance of the change, a paired-samples $t$ test for question pre- and posttest, as well as the summary score was computed. As shown in Table 2, correlations ranged from (.454 to .680) and were statistically significant $(p<.001)$.

Table 2. Pre- and Posttest Correlations Among Items Measuring Well-Being

\begin{tabular}{lccc}
\hline Well-Being Aspects & $\boldsymbol{N}$ & Correlation & $\boldsymbol{p}$ \\
\hline Mental & 79 & .548 & .000 \\
Physical & 79 & .606 & .000 \\
Emotional & 80 & .486 & .000 \\
Stress & 80 & .454 & .000 \\
Total & 78 & .680 & .000 \\
\hline
\end{tabular}

As shown in Table 3, the paired $t$ tests indicate that the positive change was statistically significant for each of the four aspects of well-being measured: mental, physical, emotional, and stress. Participants overall experienced the greatest reduction in stress score $(M=-0.83)$, followed by mental $(M=-0.62)$ and emotional $(M=-0.53)$ with the least reduction in physical well-being $(M=-.34)$.

Table 3. Paired Differences Between Pre- and Posttest Wellness Measures

\begin{tabular}{lccccccc}
\hline Well-Being Aspects & & & \multicolumn{5}{c}{$95 \%$ CI } \\
\cline { 5 - 6 } (Pretest - Posttest) & $M$ & $S D$ & $S E M$ & Lower & Upper & $t$ & $N$ \\
\hline Mental & -0.62 & 0.65 & 0.07 & -0.77 & -0.48 & $-8.53^{*}$ & 78 \\
Physical & -0.34 & 0.68 & 0.08 & -0.49 & -0.19 & $-4.49^{*}$ & 78 \\
Emotional & -0.53 & 0.73 & 0.08 & -0.69 & -0.36 & $-6.44^{*}$ & 79 \\
Stress & -0.83 & 0.81 & 0.09 & -1.00 & -0.65 & $-9.14^{*}$ & 79 \\
Total & -2.32 & 1.83 & 0.21 & -2.73 & -1.91 & $-11.22^{*}$ & 77 \\
\hline
\end{tabular}

Note. $\mathrm{CI}=$ confidence interval.

${ }^{*} p<.001$. 


\section{Discussion}

The findings demonstrate first, that changes in subjective well-being can be measured using the Happiness Mini-Survey, and second, that participants experienced statistically significant increases in subjective well-being across all four dimensions (mental, physical, stress, and emotional). This supports the work of other researchers on workplace interventions and well-being, such as Lomas, Medina, Ivtzan, Rupprecht, and Eiroa-Orosa (2017) finding that training on mindfulness training was able to decrease stress and anxiety, while increasing general well-being. These findings are comparable to those of Marx, Strauss, Williamson, Karunavira and Taravajra (2014), who used an adapted version of mindfulness-based cognitive therapy for employee well-being and identified using pre-post techniques, where the researchers similarly found improvements in employee's subjective physical, emotional, and stress scores. While Marx et al (2014) did not include a comparative overall mental health metric, their study measured employee perception of mood improvement, and their findings of improved mood is supported by our findings of improved subjective mental well-being.

Because multiple class topics were covered, further research should be conducted to identify which classes offer the greatest improvement in subjective well-being with a more diverse audience rather than in only one workplace. Additionally, testing other classes and including other physically based classes such as yoga is recommended, recognizing that which classes are beneficial may vary per organization based on each organizations culture and employee needs. There is also a question as to how much the act of simply sitting and not working for $1 \mathrm{hr}$ affected the outcome measured; thus, a recommendation would be to perform a similar test but provide a control group that does not participate in any class, but the difficulties of doing this in an organizational setting where employee time is at a premium and participation in programs is voluntary must be acknowledged. Additionally, a longitudinal study could be utilized to evaluate whether the benefit received from participation is only short-term, or whether participants continue to gain value from their participation in the classes.

The attendance numbers as a ratio of total employees (18.4\%) for the Wellshift programs is typical of that reported in other studies (Russell et al., 2016; Spence, 2015; Stansfeld et al., 2015). One factor for well-being program coordinators and human-resource managers to consider is how to change organizational culture so that employees prioritize attendance in well-being classes, when employees are faced with performance goals and must also prioritize their time among multiple projects and tasks.

\section{Potential Uses for the Happiness Mini-Survey}

While some may find the Happiness Mini-Survey too simplistic, there are a number of situations in which it can be a useful measurement tool. First, well-being practitioners teaching classes can use it to let participants self-report their improvement. Teachers can use it as an individual and cumulative group scoring tool. In Edwards' (2016) initial uses of the Happiness Mini-Survey in prior small group settings, participants were encouraged to total up their own pre- and postsurvey measurements, share any improvement, and explain what aspect of the class they felt most contributed to their subjective evaluation of improvement in well-being. This feedback is very useful to program developers in understanding which parts of the program are the most helpful and also for participants in cognitively recognizing the positive effect that participating in the program had on them. Further research is needed into whether this cognitive recognition of benefit may encourage participants to participate in more programs. 
Second, not all organizations have the budget, time, or inclination to pay for longer, time-consuming happiness or well-being surveys. For organizations that do not want to invest in a more rigorous measurement mechanism at the onset of developing a well-being program, the Happiness MiniSurvey is a quick, easy-to-use tool for evaluating programs brought into the organization to improve well-being.

Further research is recommended to determine whether, in addition to assessing well-being programs, the Happiness Mini-Survey would be valid as an ongoing measure employers could use to gauge overall employee well-being levels on a monthly, quarterly, or biannual basis. If only doing employee well-being reporting on an annual basis, it is recommended that a more in-depth measurement tool be used for more granular evaluation. Before use on a larger scale basis, it is recommended that more validation studies be performed utilizing the Happiness Mini-Survey to analyze whether any problems exist with either discriminative or predictive validity.

\section{Limitations}

Some limitations were present in this study. First, the researchers were not able to use a control group. It is possible that simply from sitting in any room and not working, employees may have experienced some improvement in their pre- and posttest scores on the Happiness Mini-Survey. Further research using a control group is recommended. Additionally, attendance was not taken to count number of people who participated in each class or who participated in more than one class. Another study where each individual is tracked to identify whether employees receive more benefit from taking one or more classes would be valuable. A comparison of benefit across classes was not conducted due to the small sample size; a future study could build upon these findings to compare two or more classes to determine which participants perceive as being more beneficial to their wellbeing. Also, because not all attendees turned in surveys, it is unclear whether those who chose not to complete a survey would have had similar or different reports. A study where all participants are required to complete the survey would address this limitation. Another limitation is any effects that participating in prior well-being programs prior to these classes, or external participation in wellbeing programs on their own initiative had on how employees benefitted from this class. For example, if the participants were mainly employees who participated in prior well-being initiatives or participated in well-being programs outside of work, then the sphere of benefit these classes affect is limited, and further research should be done on how to increase attendance levels. Another limitation is the lack of data regarding the cost benefit analysis of the program. Researchers were unable to access data regarding what benefits outside of the initial, subjective benefit participants received, the organization realized over time by providing well-being programs. A longitudinal study with greater access to organizational data points including items such as absenteeism, turnover, presenteeism, and performance metrics would be valuable to assess the effectiveness of well-being programs as part of organizational initiatives to improve employee health and productivity.

\section{Implications for Social Change}

This survey opens up a new dimension for how well-being programs are measured by allowing participants to cognitively evaluate pre- and postclass their subjective well-being improvement in real time. Because AET, self-efficacy, and subjective well-being all relate with how the employee thinks and feels, this is an important and yet unexplored avenue for research into what makes wellbeing programs effective. 
This pilot study also has implications for encouraging both large and small companies to consider incorporating well-being classes and programs into their employee benefits packages. Demonstrating significant changes in cost-effective ways can support managers and decision-makers' efforts to contribute to employee well-being and support their recognition of the social capital value of the workplace wellness.

\section{References}

Archer, S. (2012). Health is wealth: The rise of workplace wellness. IDEA Fitness Journal, 9, 38-44.

Asay, G. R. B., Roy, K., Lang J. E., Payne, R. L., \& Howard, D. H. (2016) Absenteeism and employer costs associated with chronic diseases and health risk factors in the U.S. workforce. Preventing Chronic Disease, 13, 150503. doi:10.5888/pcd13.150503

Baicker, K., Cutler, D., \& Song, Z. (2010). Workplace wellness programs can generate savings. Health Affairs, 29, 2. doi:10.1377/hlthaff.2009.0626

Bakker, A. B. (2015). Towards a multilevel approach of employee wellbeing. European Journal of Work and Organizational Psychology, 24, 839-843. doi:10.1080/1359432X.2015.1071423

Bera, S. (2017). Financial basics: What you should have learned about money but never did. Austin, TX: Wellshift. Retrieved on April 14, 2017, from https://www.wellshift.com/\#/activity/6d318e1a-ac20-4cd0-9466-f3a488e4e2b8

Berry, L. L., Mirabito, A. M., \& Baun, W. B. (2010). What's the hard return on employee programs? Harvard Business Review, 12, 1-17. Retrieved from https://hbr.org/2010/12/whats-the-hardreturn-on-employee-wellness-programs

Chanchal, J. N., \& Divya, D. T. (2015). Relationships between self-efficacy and subjective wellbeing of employees in an organization. Annamalai International Journal of Business Studies \& Research, 15, 35-43.

Conrad, P. (1988). Worksite health promotion: The social context. Social Science \& Medicine, 26, $485-489$.

Dolbier, C. L., Webster, J. A., McCalister, K. T., Mallon, M. W., \& Steinhardt, M. A. (2005). Reliability and validity of a single-item measure of job satisfaction. American Journal of Health Promotion, 19, 194-198. Retrieved from https://www.edb.utexas.edu/steinhardt/Files/Dolbier.McCalister.Steinhardt(2005).pdf

Eastman, W. (1996). Avoiding faculty burnout through the wellness approach. Paper presented at the Annual Conference of the Association of Canadian Community Colleges, May 26-28, 1996, Toronto, Canada.

Edwards, A. V. (2016). Initial pre/post class wellbeing survey [Handout]. Las Vegas, NV: Lift Up Vegas.

Edwards, A. V. (2017). Revised pre/post class wellbeing survey [Handout]. Austin, TX: Wellshift.

Eisenberger, R., Huntington, R., Hutchison, S., \& Sowa, D. (1986). Perceived organizational support. Journal of Applied Psychology, 71, 500-507.

Elo, A., Leppänen, A., \& Jahkola, A. (2003). Validity of a single-item measure of stress symptoms. Scandinavian Journal of Work, Environment \& Health, 29, 444-451. doi:10.5271/sjweh.752 
Fleming, A. S., Ruble, D. N., Flett, G. L., \& Van Wagner, V. (1990). Adjustment in first-time mothers: Changes in mood and mood content during the early postpartum months. Developmental Psychology, 26, 137-143.

Fredrickson, B. L. (2001). The role of positive emotions in positive psychology: The broaden-and-build theory of positive emotions. American Psychologist, 56, 218-226. doi:10.1037/0003066X.56.3.218

Hall, L. H., Johnson, J., Watt, I., Tsipa, A., \& O’Connor, D. B. (2016). Healthcare staff wellbeing, burnout, and patient safety: A systematic review. PLoS ONE, 11, 1-13. doi:10.1371/journal.pone.0159015

Hart, C. P. M., \& Cooper, C. L. (2014). Occupational stress: Toward a more Integrated framework. In N. Anderson, D. S. Ones, H. K. Sinangil, \& C. Viswesvaran (Eds.), Handbook of industrial, work \& organizational psychology: Volume 2: Organizational psychology (pp. 93-114). Thousand Oaks, CA: Sage. doi:10.4135/9781848608368.n6

Horneij, E., Holmström, E., Hemborg, B., Isberg, P., \& Ekdahl, C. (2002). Inter-rater reliability and between-days repeatability of eight physical performance tests. Advances in Physiotherapy, 4, 146-160. doi:10.1080/14038190260501596

Howard, J. (2017). The powerful language of the nervous system. Austin, TX: Wellshift. Retrieved on April 14, 2017, from https://www.wellshift.com/\#/activity/fabc099b-418e-4709-85dcd419b7f3ec29

Ilies, R., Aw, S. S. Y., \& Pluut, H. (2015). Intraindividual models of employee wellbeing: What have we learned and where do we go from here? European Journal of Work and Organizational Psychology, 24, 827-838. doi:10.1080/1359432X.2015.1071422

Insel, T. R. (2008). Assessing the economic costs of serious mental illness. The American Journal of Psychiatry. 165, 663-665

Iverson, R. D., Olekalns, M., \& Erwin, P. J. (1998). Affectivity, organizational stressors, and absenteeism: A causal model of burnout and its consequences. Journal of Vocational Behavior, 52, 1-23. doi:10.1006/jvbe.1996.1556

Jasso, J. (2017). Don't hate. Meditate. Austin, TX: Wellshift. Retrieved on April 14, 2017, from https://www.wellshift.com/\#/activity/65eeb598-e883-4b73-936c-ecd98d310c6e

Järvholm, S., Broberg, M., \& Thurin-Kjellberg, A. (2014). The choice of pre-implantation genetic diagnosis (PGD), a qualitative study among men and women. Journal of Reproductive \& Infant Psychology, 32, 57-69. doi:10.1080/02646838.2013.851372

Kaare, K. K., \& Otto, T. (2015). Smart health care monitoring technologies to improve employee performance in manufacturing. Procedia Engineering, 100, 826-833. doi:10.1016/j.proeng.2015.01.437

Kahneman, D., \& Krueger, A. B. (2006). Developments in the measurement of subjective wellbeing, Journal of Economic Perspectives, 20, 3-24.

Krainz, K. D. (2015). Enhancing wellbeing of employees through corporate social responsibility context. Megatrend Review, 12, 137-153.

Krystal, A. D. (2005). The effect of insomnia definitions, terminology, and classifications on clinical practice. Journal of the American Geriatrics Society, 53, S258-S263.

Kuykendall, L., \& Tay, L. (2015). Employee subjective wellbeing and physiological functioning: An integrative model. Health Psychology Open, 2, 1-11. doi:10.1177/2055102915592090 
Lee, J. S., Joo, E. J., \& Choi, K. S. (2013). Perceived stress and self-esteem mediate the effects of work-related stress on depression. Stress and Health, 29, 75-81. doi:10.1002/smi.2428

Lomas, T., Medina, J. C., Ivtzan, I., Rupprecht, S., \& Eiroa-Orosa, F. J. (2017). The impact of mindfulness on the wellbeing and performance of educators: A systematic review of the empirical literature. Teaching and Teacher Education, 61, 132-141. doi:10.1016/j.tate.2016.10.008

Marx, R., Strauss, C., Williamson, C., Karunavira, \& Taravajra. (2014). The eye of the storm: A feasibility study of an adapted mindfulness-based cognitive therapy (MBCT) group intervention to manage NHS staff stress. The Cognitive Behaviour Therapist, 7, e18. doi:10.1017/S1754470X14000300

Meade, O., MacLennan, S. J., Blake, H., Coulson, N. (2009). Workplace complementary and alternative therapies for hospital-site staff. International Journal of Workplace Health Management, 2, 258-274. doi:10.1108/17538350910993449

Meh. (n.d.). In Merriam-Webster's online dictionary. Retrieved from https://www.merriamwebster.com/dictionary/meh

Miraglia, M., \& Johns, G. (2016). Going to work ill: A meta-analysis of the correlates of presenteeism and a dual-path model. Journal of Occupational Health Psychology, 21, 261-283.

Mitchell, T. R., \& Daniels, D. (2003). Motivation. In W. C. Borman, D. R. Ilgen, R. J. Klimoski, \& I. B. Weiner, (Eds.) Handbook of psychology: Volume 12: Industrial and organizational psychology (pp. 225-254). Hoboken, NJ: John Wiley \& Sons.

Mukhopadhyay, S., \& Wendel, J. (2013). Evaluating an employee wellness program. International Journal of Health Care Finance and Economics, 13, 173-199. doi:10.1007/s10754-013-9127-4

National Alliance on Mental Illness. (n.d.). Mental health conditions. Retrieved from http://www.nami.org/Learn-More/Mental-Health-Conditions

Parks, K., \& Steelman, L. (2008). Organizational wellness programs: A meta-analysis. Journal of Occupational Health Psychology, 13, 58-68.

Parker, G. B., \& Hyett, M. P. (2011). Measurement of wellbeing in the workplace: The development of the work wellbeing questionnaire. The Journal of Nervous and Mental Disease, 199, 394-397. doi:10.1097/NMD.0b013e31821cd3b9

Phillips, J. (2017). Taming the tigers: How to avoid chronic stress. Austin, TX: Wellshift. Retrieved April 14, 2017, from https://www.wellshift.com/\#/activity/4bae2cf7-c594-4f63-8800e2a7c58eac76

Pohling, R., Buruck, G., Jungbauer, K. L., \& Leiter, M. P. (2016). Work-related factors of presenteeism: The mediating role of mental and physical health. Journal of Occupational Health Psychology, 21, 220-234.

PricewaterhouseCoopers. (2017). Creating a mentally healthy workplace: Return on investment analysis. Melbourne, Australia: Beyondblue, National Mental Health Commission. Retrieved from https://www.headsup.org.au/docs/default-source/resources/bl1269-brochure---pwc-roianalysis.pdf?sfvrsn $=6$

Russell, J., Berney, L., Stansfeld, S., Lanz, D., Kerry, S., Chandola, T., \& Bhui, K. (2016). The role of qualitative research in adding value to a randomized controlled trial: Lessons from a pilot study of a guided e-learning intervention for managers to improve employee wellbeing and reduce sickness absence. Trials, 17, 396. doi:10.1186/s13063-016-1497-8 
Scarpello, V., \& Campbell, J. P. (1983). Job satisfaction: Are all the parts there? Personnel Psychology, 36, 577-600.

Schmid, J. A., Jarczok, M. N., Sonntag, D., Herr, R. M., Fischer, J. E., \& Schmidt, B. (2017). Associations between supportive leadership behavior and the costs of absenteeism and presenteeism: An epidemiological and economic approach. Journal of Occupational and Environmental Medicine, 59, 141-147.

Shuck, B., \& Reio, T. (2014). Employee engagement and wellbeing: A moderation model and implications for practice. Journal of Leadership \& Organizational Studies, 21, 43-58.

Slemp, G. R., Kern, M. L., \& Vella-Brodrick, D. A. (2015). Workplace well-being: The role of job crafting and autonomy support. Psychology of Well-Being, 5, 7. doi:10.1186/s13612-015-0034-y

Spence, G. B. (2015). Workplace wellbeing programs: If you build it they may NOT come ... because it's not what they really need! International Journal of Wellbeing, 5, 109-124. doi:10.5502/ijw.v5i2.7

Stansfeld, S. A., Berney, L., Bhui, K., Chandola, T., Costelloe, C., Hounsome, N., ... Russell, J. (2015). Pilot study of a randomised trial of a guided e-learning health promotion intervention for managers based on management standards for the improvement of employee wellbeing and reduction of sickness absence: The GEM (Guided E-learning for Managers) Study. Public Health Research, 3, 2050-4381. doi:10.3310/phr03090

Tabak, R. G., Hipp, J. A., Marx, C. M., \& Brownson, R. C. (2015). Workplace social and organizational environments and healthy-weight behaviors. Plos ONE, 10, 1. doi:10.1371/journal.pone.0125424

Tan, L., Wang, M.-J., Modini, M., Joyce, S., Mykletun, A., Christensen, H., \& Harvey, S. B. (2014). Preventing the development of depression at work: A systematic review and meta-analysis of universal interventions in the workplace. BMC Medicine, 12, 74. doi:10.1186/1741-7015-1274

Warr, P. (2014). How to think about and measure psychological wellbeing. In M. Wang, R. R. Sinclair and L. E. Tetrick (Eds.), Research methods in occupational health psychology. New York, NY: Psychology Press.

Wells, A. (2006). Cognitive therapy case formulation in anxiety disorders. In N. Terrier (Ed.), Case formulation in cognitive behaviour therapy: The treatment of challenging and complex cases (pp. 52-80). London, United Kingdom: Routledge.

Weinberger, M. (2017). Wellshift class schedule. Austin, TX: Wellshift.

Weiss, H. M., \& Cropanzano, R. (1996). Affective events theory: A theoretical discussion of the structure, causes and consequences of affective experiences at work. In B. M. Staw \& L. L. Cummings (Eds), Research in organizational behavior (Vol. 18, pp. 1-74). Greenwich, CT: JAI Press.

Wellshift (2017). Wellshift. Retrieved April 14, 2017, from http://www.wellshift.com

Zamcheck, K. (2017). Empower yourself: Present like a pro. Austin, TX: Wellshift. Retrieved on April 14, 2017, from https://www.wellshift.com/\#/activity/470404f8-ebc8-41ef-87cd-3a52e23f0058

Zungu, L. I., \& Setswe, K (2007). An integrated approach to the prevention and promotion of health in the workplace: A review from international experience. SA Family Practice, 49, 6-9. doi:10.1080/20786204.2007.10873564 
The Journal of Social, Behavioral, and Health Sciences is an open-access, peer-reviewed, online interdisciplinary journal focusing on research findings that address contemporary national and international issues. Its objectives are to (a) encourage dialogue between scholars and practitioners in the social, behavioral, and health sciences that fosters the integration of research with practice; (b) promote innovative models of interdisciplinary collaboration among the social, behavioral, and health sciences that address complex social problems; and (c) inform the relationship between practice and research in the social, behavioral, and health sciences.

Walden University Publishing: http://www.publishing.waldenu.edu 